\title{
FATORES SOCIOECONÔMICOS RELACIONADOS À PRODUÇÃO DE PLANTAS MEDICINAIS
}

\author{
Elenice Parizotto Stremel* \\ Geysler Rogis Flor Bertolini** \\ Dile Pontarolo Stremel ${ }^{* * *}$ \\ Adriana Maria de Grandi****
}

RESUMO: Este estudo objetivou identificar importantes aspectos socioeconômicos e entender a dinâmica do cultivo e produção de plantas medicinais a partir de trabalhos publicados, focando as bases de periódicos, teses e dissertações, disponibilizados pela CAPES, de 2008 até 2013. A metodologia aplicada foi uma pesquisa bibliográfica comparativa. A busca das referências se deu pelas palavras-chaves: plantas medicinais; análise socioeconômica; cooperativa; fitoterapia; e outras como agricultura familiar; comercialização; e desenvolvimento rural. De acordo com os resultados, o fator políticas públicas destacou-se dos demais, mostrando ser relevante para manter os negócios das famílias de produtores rurais, principalmente por promover ações que levam a incorporar renda aos produtos de baixo valor agregado; por outro lado proporcionam programas de financiamento a juros baixos e ações de combate à desigualdade social.

PALAVRAS-CHAVE: Agricultura Familiar; Fatores; Pesquisa Socioeconômica.

\section{SOCIAL AND ECONOMIC FACTORS RELATED TO THE PRODUCTION OF MEDICINAL HERBS}

ABSTRACT: Relevant social and economic aspects were identified to understand the dynamics of culture and production of medicinal herbs as from publications in scientific journals, theses and dissertations provided by CAPES between 2008 and 2013. Current comparative bibliographical research was based on references

\footnotetext{
Mestranda do Programa de Pós-Graduação em Desenvolvimento Rural Sustentável da Universidade Estadual do Oeste do Paraná (UNIOESTE), Campus Marechal Cândido Rondon (PR), Brasil.

E-mail: nice_pa@hotmail.com

** Docente Doutor do Programa de Pós-Graduação em Desenvolvimento Rural Sustentável da Universidade Estadual do Oeste do Paraná (UNIOESTE), Campus Marechal Cândido Rondon (PR), Brasil.

*** Docente Doutor da Universidade Federal do Paraná (UFPR), Setor Palotina (PR), Brasil.

***** Docente Doutora do Programa de Pós-Graduação em Desenvolvimento Rural Sustentável da Universidade Estadual do Oeste do Paraná (UNIOESTE), Campus Marechal Cândido Rondon (PR), Brasil.
} 
with the keywords: medicinal herbs, social and economic analysis, cooperative, phytotherapy, family agriculture, commercialization and rural development. Results show that the factor 'public policies' was predominant and showed the importance of maintaining family business by rural producers. The latter may be achieved by incorporating earnings to products of low aggregate value. On the other hand, they provide loan programs at low interests and activities against social inequality.

KEY WORDS: Family Agriculture; Factors; Socio-Economic Research.

\section{INTRODUÇÃO}

A agricultura familiar está presente nas características socioeconômicas de mais de $60 \%$ dos Estados do Brasil. Com o aumento do consumo de medicamentos fitoterápicos, a produção de plantas medicinais tem sido uma alternativa para os pequenos produtores. Por conta disso, esta atividade tem ganhado espaço na agricultura familiar. Atualmente, os fitoterápicos constituem importante fonte de inovação em saúde, sendo objeto de interesses empresariais privados e fator de competitividade do Complexo Produtivo da Saúde (PEREIRA FILHO, 2001 apud LOURENZANI; LOURENZANI; BATALHA, 2004, p. 3). Muitos produtores rurais estão despertando para esse nicho de mercado que, por sua vez, pode lhes proporcionar maior renda e diversificação de cultivos. A adaptação dos produtores quanto à necessidade de adequações na produtividade se dá ainda de forma lenta. Com o aumento do consumo de medicamentos fitoterápicos, a produção de ervas medicinais é uma alternativa para a agricultura familiar (PEREIRA FILHO, 2001).

A agricultura familiar tem um papel estratégico na economia brasileira. Recentemente, a Secretaria Social da Presidência da República chamou a atenção para a importância da agricultura familiar, destacando que ela responde por $38 \%$ do valor da produção e é responsável por garantir a segurança alimentar do país ao gerar produtos da cesta básica consumida pelos brasileiros (CULTI, 2010, p. 8).

Ressalta-se que os produtores têm optado pela diversificação da produção ao invés da especialização, ou seja, mesclam diferentes espécies principalmente com o intuito de garantir renda durante todo o ano. Além disso, técnicos afirmam que tal diversificação traz como vantagens a redução do uso de agrotóxicos e facilita o cultivo 
orgânico. Portanto, os benefícios alcançados pelo cultivo e exploração sustentavel de plantas medicinais no Brasil não se restringem apenas às suas propriedades medicinais, mas constituem também um bom negócio para os agricultores dispostos a investir em seu cultivo, como alternativa de renda, ou até mesmo como atividade principal (LOURENZANI; LOURENZANI; BATALHA, 2004, p. 19).

Há uma vasta publicação científica sobre plantas medicinais, porém poucos estudos têm relação com aspectos socioeconômicos. Os estudos relacionados às propriedades curativas e benefícios das plantas, assim como o manejo, estão em evidência, ficando uma lacuna na questão de viabilidade socioeconômica para a agricultura familiar.

O cultivo de plantas medicinais tem sido incentivado pelo Ministério do Desenvolvimento Agrário (MDA) através das políticas públicas, no entanto os desafios são consideráveis para se alcançar os resultados desejados, principalmente no aumento de renda e agregação de valor à produção, fatores estes que dependem de infraestrutura, estudos científicos e boas práticas de produção e fabricação. Além destas questões, cada produtor lida com suas peculiaridades políticas e locais e dependem intrinsecamente de modos de gestão cooperativistas com dinâmicas muitas vezes não articuladas com a sua realidade. As características de produção e experiências variam de acordo com cada arranjo de famílias envolvidas em cultivos de plantas medicinais. Um dos maiores desafios está nos projetos das novas diretrizes do Ministério da Saúde, estabelecendo uma política inter-setorial para o desenvolvimento socioeconômico na área de plantas medicinais e fitoterápicos (BRASIL, 2006). Atender a esta e a outras expectativas requer maior amadurecimento e profissionalismo de setores da sociedade elencados para apoiar a produção, uma vez que demandam profissionais capacitados e formação específica, passando inclusive por criação de novos cursos técnicos e tecnológicos e de gestão, que proporcionem assistências técnicas mais especializadas. Propostas como estas ainda requerem um estudo aprofundado da realidade a nível nacional.

Nesse sentido, Corrêa e Alves (2008, p. 1) concluem que existe um aumento da oferta e demanda de plantas medicinais, entretanto o sistema produtivo encontrase deficiente e despreparado para atender a esse novo mercado. O maior desafio é agregar valor a esse produto, sendo que a legislação brasileira, a ausência de linhas de crédito específicas e o investimento inicial são considerados os principais entraves 
à produção.

Atualmente, o Paraná é o principal produtor de plantas medicinais do país, sendo responsável por aproximadamente $90 \%$ da produção brasileira. O Estado produz 15 mil toneladas/ano, retiradas de uma área de três mil hectares, com a participação de 1.100 agricultores familiares na atividade. Além de atacadistas, ervanários e farmácias de manipulação, o mercado de plantas medicinais também está associado a indústrias diversas, como a farmacêutica, de cosméticos e perfumaria, de alimentos e bebidas, entre outras. Fiscalizações prévias do Conselho Regional de Engenharia e Agronomia (CREA) apontam que, apesar do Estado ser o principal produtor, ainda há uma falta de assistência técnica para que os agricultores aprimorem as culturas. O CREA ainda pretende fazer um levantamento da cadeia produtiva e mostrar que a assistência técnica no Paraná está deficitária em recursos humanos (HISATOMI, 2013).

De acordo com o fiscal Ricardo Araújo (apud HISATOMI, 2013), "a maior parte da produção da cadeia de plantas medicinais no Estado é realizada por pequenos produtores, que dependem do cooperativismo e do acompanhamento técnico para o sustento de suas famílias".

Seria possível identificar fatores socioeconômicos preponderantes nos estudos realizados com plantas medicinais? A partir desta questão o objetivo deste estudo foi fazer um levantamento bibliográfico dos últimos seis anos de publicações envolvendo o cultivo de plantas medicinais, além de sua relação com fatores socioeconômicos, principalmente através da agricultura familiar, visando ampliar e contribuir com diagnósticos mais precisos e realistas sobre este assunto. Outro objetivo também foi direcionar tomadas de decisões mais eficazes para os produtores de plantas medicinais, assim como facilitando eixos norteadores de ações governamentais quanto ao cultivo de plantas medicinais através da agricultura familiar.

\section{MATERIAIS E MÉTODOS}

Procurou-se desenvolver uma revisão bibliográfica, entre os anos de 2008 a 2013, através de consulta em periódicos nacionais e internacionais, teses e 
dissertações no portal de periódicos da Coordenação de Aperfeiçoamento de Pessoal de Nível Superior (CAPES). Foram selecionados vinte trabalhos publicados, sendo dois periódicos internacionais no período anteriormente mencionado (ANEXO A). Os critérios para inclusão foram trabalhos que abordassem dimensões de relevância para definir uma relação entre a produção de plantas medicinais e a realidade social e econômica de cada arranjo produtivo local, possibilitando quantificar e qualificar tendências através de análise quantitativa proveniente de uma matriz de fatores críticos observados versus percentuais identificados dos fatores nas publicações pesquisadas. Realizou-se o levantamento dos percentuais de publicações em comum, tanto em periódicos de interesse com Qualis como dissertações de mestrado, considerando a nota do trabalho aquela recebida pelo respectivo programa de pósgraduação na área de publicação.

Visando identificar implicações nas questões socioeconômicas, proferiu-se uma minuciosa análise dos resultados gerados a partir de cada trabalho. Os artigos e teses foram separados conforme aproximação de alguns fatores socioeconômicos identificados como aspectos sociais, culturais, tecnológicos e políticas públicas.

\section{RESULTADO E DISCUSSÃO}

\subsection{ASPECTOS SOCIOECONÔMICOS DOS PRODUTORES RURAIS}

O levantamento no portal da CAPES, de publicações que abordassem a produção de plantas medicinais pela agricultura familiar, apontou implicações econômicas e sociais da atividade e uma relação de dependência complexa entre estes dois aspectos. Em um primeiro momento, os artigos foram analisados principalmente quanto aos resultados encontrados. Na Tabela 1 é possível observar artigos, dissertações e teses até 2013. As publicações elencadas também fazem parte da mesma Tabela 1: ASA: Acta Scientiarum Agronomy; RBA: Revista Brasileira de Agroecologia; RBF: Revista Brasileira de Farmacognosia; DM: Dissertações de mestrado; RAG: Revista Agroalimentaria; RAM: Revista Ambiência; BJP: Brazilian Journal of Pharmacognosy; RABB: Revista Acta Botânica Brasílica; REF: Rev. Esc. 
Enferm.; RBPM: Revista Brasileira de Plantas Medicinais; CR: Ciência Rural; CSS: Ciência \& Saúde Coletiva; RSP: Rev. Saúde Pública; JEE: Journal of Etbnobiology and Ethnomedicine; e JAA:Journal of Agricultural Science.

Tabela 1. Fontes pesquisadas de 2008 a 2013.

\begin{tabular}{lccc}
\hline Publicação & Avaliação Capes & Quantidade & Percentual \\
\hline ASA & B2 & 1 & 5 \\
RBA & B5 & 1 & 5 \\
RBF & B3 & 1 & 5 \\
DM & $5,3,4,9\left(^{*}\right)$ & 4 & 20 \\
RAG & B5 & 1 & 5 \\
RAM & B1 & 1 & 5 \\
BJF & B1 & 1 & 5 \\
RABB & B2 & 1 & 5 \\
REF & B3 & 1 & 5 \\
RBPM & B4 & 3 & 15 \\
CR & B5 & 1 & 5 \\
CSS & B5 & 1 & 5 \\
RSP & B5 & 1 & 5 \\
JEE & A2 $(* *)$ & 1 & 5 \\
JAS & B1 (**) & 1 & 5 \\
\hline Total & & 20 & 100 \\
\hline
\end{tabular}

Legenda: ( * Consulta por (área de avaliação): 5-Pereira Júnior (2011); 3-Ghislene, G. A. (2012); 4-Souza(2012). (**) Interdisciplinar

A partir dos resultados da Tabela 2, observou-se a possibilidade de agrupar algumas dimensões e fatores de influência que afetaram ou contribuíram para os aspectos socioeconômicos dos produtores rurais. Há uma discrepância entre políticas públicas e os demais dados, o que já era de se esperar, já que a dependência de ações governamentais ainda é o que conduz a possibilidade de manter os negócios para as famílias de produtores rurais e incorporar renda aos produtos de baixo valor agregado, através de programas de financiamento a juros baixos e outras ações de combate à desigualdade social. 
A Tabela 3 (ANEXO A) contém as informações que direcionam para tomada de decisão visando estabelecer as dimensões importantes da pesquisa que resultaram na Tabela 2. Os fatores observados foram construídos com base na identificação de temas relevantes e de interesse na problemática socioeconômica, ou que possam afetar significativamente indicadores de desempenho relacionados a este escopo.

Tabela 2. Dimensões relevantes levantadas

\begin{tabular}{l|c|c}
\hline Fatores Críticos Observados & Dissertações e Artigos & Percentual (\%) \\
\hline Social & 2 & 10 \\
Cultural & 3 & 15 \\
Tecnológico & 4 & 20 \\
Políticas Públicas & 11 & 55 \\
\hline Total & $\mathbf{2 0}$ & $\mathbf{1 0 0}$ \\
\hline
\end{tabular}

\subsection{FATORES OBSERVADOS}

\subsubsection{Social}

Um dos objetivos relacionados aos aspectos sociais de cultivadores de plantas medicinais é o desenvolvimento rural sustentável. No trabalho desenvolvido por De Souza et al. (2008), nota-se claramente que implantar programas de geração de renda não é o maior desafio, mas sim buscar alternativas sociais para vencer aspectos individualistas e de extrema pobreza. $\mathrm{O}$ aspecto social foi bem identificado no trabalho de Ghisleni (2012), por meio de ações de estratégias de reprodução social local, que levaram a uma melhora no resgate familiar/cultural, uso das plantas medicinais, troca de experiências, conhecimento técnico de produção, incentivo do setor público e parcerias. Estes trabalhos mostram a importância do aspecto humano e social como contribuidor para a agricultura familiar.

\subsubsection{Cultural}

Foram observados em três trabalhos o aspecto cultural. Aguiar et al. (2009) relatam a importância das técnicas tradicionais de cultivo na Amazônia, capazes de 
gerar renda. Detectar o perfil de consumidores também foi importante, $\theta$ uma vez que traz a necessidade de maiores esclarecimentos sobre forma de cultivo, correta identificação botânica, informações ao consumidor, qualidade e eficácia dos produtos e seu uso (ETHUR et al., 2011). Já Ceolin et al. (2011) relatam a necessidade da construção do conhecimento relacionado ao uso de plantas medicinais pelas famílias de agricultores, buscando integrar o saber popular e o científico, incentivando o lucro e o bem-estar.

\subsubsection{Tecnológico}

Apesar da relativa importância no desenvolvimento de novos produtos com valores de mercado, a contribuição para o aspecto socioeconômico do produtor rural atualmente é conturbada, não dependendo do produtor exclusivamente, mas sim de avanços no campo científico para comprovação de eficácia e efeitos toxicológicos (USTULIN et al., 2009; BOCHNER et al., 2012; SOUZA-MOREIRA; SALGADO; PIETRO, 2010). Por outro lado, a partir de análises técnicas em trabalhos para caracterização da produção, identificou-se necessidade de intervenções imediatas no processo de secagem com objetivo de atender às expectativas de melhora da renda dos produtores rurais (TRENTO FILHO; MENON; CORRÊA JUNIOR, 2010).

\subsubsection{Políticas Públicas}

Fica claro que intervenções contribuirão indiretamente para o campo econômico-social. A efetiva fiscalização dos órgãos ambientais visando garantia da qualidade do produto, definição e implementação de política de garantia de preço mínimo para o produto são necessidades para a sustentabilidade (LINHARES, 2010). O fortalecimento da agricultura familiar passa por um conjunto de iniciativas dos próprios agricultores enquanto atores sociais do seu próprio destino e desenvolvimento, mas também por ações ativas do Estado (GRISA; GAZOLLA; SCHNEIDER, 2010; LIMA; COELHO-FERREIRA; OLIVEIRA, 2011; SOUZA, 2012). Neste caso nota-se a necessidade de implantar este sistema onde a vulnerabilidade social é significativa. 
Outros trabalhos detectam a necessidade da intervenção governamental para garantir a infraestrutura necessária ao campo, como em Pereira Júnior (2011), e aspectos autossustentáveis, conforme Gallo et al. (2012), ou para divulgar informações e conhecimentos para aumentar o consumo, como apresentado em Souza, Pereira e Fonseca (2012). De forma geral, as questões da intervenção do Estado para melhora da inclusão social ficam claras no trabalho de Sorte Junior (2012), esclarecendo que as oportunidades de negócios ainda são pouco exploradas no Brasil e dependem de articulações que levem a uma melhor racionalidade na exploração de recursos. No exterior não é diferente, soluções de sustentabilidade e melhoria das condições econômicas sociais, relatados por Kanwat et al. (2012) e Bergmeier et al. (2013), passam por ajustes governamentais.

\section{CONSIDERAÇÕES FINAIS}

É importante mencionar que o levantamento de situações relacionadas anteriormente também está ligado às diversidades nas regiões estudadas e dependerão de estudos mais aprofundados das características regionais para compreender melhor as especificidades. Os fatores sociais, ambientais, políticas públicas e culturais, apontados neste trabalho, têm sido os mais encontrados nas bibliografias quanto a relevâncias positivas ou negativas relacionadas aos aspectos socioeconômicos dos produtores de plantas medicinais. Ainda não podemos definir um fator preponderante, porém é possível direcionar a importância de levantamentos técnicos futuros, que possibilitarão estratégias regionais mais efetivas ampliando a melhoria do desenvolvimento rural sustentável. Apesar de haver ações para todo o território nacional em relação às plantas medicinais, é fato que programas múltiplos são fundamentais para resolver as questões de desigualdades sociais, culturais, tecnológicas e de políticas públicas, mas terão de avançar com a participação efetiva da sociedade que traçará as demandas necessárias. 


\section{REFERÊNCIAS}

AGUIAR, J. et al. Reprodução socioeconômica e cultural através do manejo de sistemas. Revista Brasileira de Agroecologia, v. 4, n. 2, p. 4195-4198, 2009.

BERGMEIER, E. et al. Diversity and use of ethno-medicinal plants in the region of Swat, North Pakistan. 2013. Journal of Ethnobiology and Ethnomedicine, v. 9, p. $25,2013$.

BOCHNER et al. Problemas associados ao uso de plantas medicinais comercializadas no Mercadão de Madureira, município do Rio de Janeiro, Brasil. Revista Brasileira de Plantas Medicinais, Botucatu, v. 14, n. 3, 2012.

BORBA, ELDER.T.; HARTER-MARQUES, B.; CITADINI-ZANETTE, V. Produção orgânica de calêndula: um estudo de caso. Ciência Rural, Santa Maria, v. 42, n. 11, p.4, set. 2012.

BRASIL. Decreto no ${ }^{\mathbf{0}}$ 5813, de 22 de junho de 2006. Aprova a Política Nacional de Plantas Medicinais e Fitoterápicos e dá outras providências. 2006.

CEOLIN, T. et al. Plantas medicinais: transmissão do conhecimento nas famílias de agricultores de base ecológica no Sul do RS. Rev. esc. enferm. USP., São Paulo, v. 45, n. 1, mar. 2011.

CORREAA, C.C.; ALVES, F.A.L. Plantas medicinais como alternativa de negócios: Caracterização e importância. In: CONGRESSO DA SOCIEDADE BRASILEIRA DE ECONOMIA, ADMINISTRAÇÃO E SOCIOLOGIA RURAL, 46., 2008. Anais eletrônicos... Rio Branco, SOBER, 2008. Disponível em: < http://www.sober.org.br/ palestra/9/418.pdf> . Acesso em: 28 out. 2013.

CULTI, M.N. Prefácio. In: BORINELLI, B.; DOS SANTOS, L. M. L.; PITAGUARI, S. O. Economia solidária em Londrina aspectos conceituais e experiência Institucional. Londrina: UEL, 2010. p. vii-xi.

DE SOUZA; MORETTI; DA COSTA; PINTO. Aspectos da exploração agropecuária das famílias assentadas em duas vilas rurais localizadas no município de Rio Negro, Estado do Paraná. Acta Scientiarum Agronomy, v. 30, n. 1, p. 45-55, jan. 2008. 
ETHUR, L.Z. et al. Comércio formal e perfil de consumidores de plantas medicinais e fitoterápicos no município de Itaqui-RS. Revista Brasileira de Plantas Medicinais, Botucatu, v. 13, n. 2, 2011.

GALLO, E. et al. Saúde e economia verde: desafios para o desenvolvimento sustentável e erradicação da pobreza. Ciência \& Saúde Coletiva, v. 17, n. 6, p. 1457, jun. 2012.

GHISLENI, G.A. Associação de agricultores Peri urbanos: uma alternativa de desenvolvimento local na região missioneira do Rio Grande do Sul. 2012. Dissertação (Mestrado em Gestão Estratégica de Organizações) - Universidade Regional Integrada do Alto Uruguai e das Missões, 2012.

GRISA, C.; GAZOLLA, M.; SCHNEIDER, S. A "Produção invisível" na agricultura familiar: autoconsumo, segurança alimentar e políticas públicas de desenvolvimento rural. Revista Agroalimentaria, v. 16, n. 31, p. 65, jul./dez. 2010.

HISATOMI, M. A. Paraná domina mercado de plantas medicinais. Bem Paraná: O Jornal do Estado, Curitiba, 21 de agosto de 2013. Caderno Ciência \& Meio Ambiente.

KANWAT, M. et al. Impact of socio-economic factors on adoption of farmers towards cultivation of medicinal Plants in Udaipur Division of Rajasthan State in India. Journal of Agricultural Science, v. 4, n. 2, 2012.

LIMA, P.G.C.; COELHO-FERREIRA, M.; OLIVEIRA, R. Plantas medicinais em feiras e mercados públicos do distrito florestal sustentável da BR-163, Estado do Pará, Brasil. Revista Acta Botânica Brasílica, v. 25, n. 2, p. 422-434, 2011.

LINHARES, J.F.P.L. Sustentabilidade socioambiental da extração de janaúba (Himatanthus Willd. Ex Schult.) no município de Alcântara, MA, Brasil. São Luís, UFMA. 2010. 116f. Dissertação (Mestrado Sustentabilidade de Ecossistemas) - Universidade Federal do Maranhão, Departamento de Oceanografia e limnologia, São Luís, 2010.

LOURENZANI, W.L.; LOURENZANI, A.E.B.S.; BATALHA, M.O. Barreiras e oportunidades na comercialização de plantas medicinais provenientes da agricultura familiar. Informações Econômicas, v. 34, n. 3, mar. 2004. 
PEREIRA FILHO, J. Cresce o espaço das plantas na medicina. Gazeta Mercantil, São Paulo, 11 a 17 abr. 2001. Por Conta Própria, p. 8-9.

PEREIRA JÚNIOR, L.R.P. Florística e fitossociologia da caatinga, aspectos socioeconômicos e potenciais do uso fitoterápico pela população rural de Monteiro, Paraíba. 2011. 117f. Dissertação (Mestrado em Agronomia) - Universidade Federal da Paraíba, 2011.

SORTE JUNIOR, W.F.S. Uso do conhecimento tradicional para promover a inclusão socioeconômica de comunidades locais. Revista Saúde Pública, São Paulo, v. 46, n. 3, abr.jun. 2012.

SOUZA, F. M. Caracterização socioeconômica e ambiental de produtos florestais não madeireiros de famílias agroextrativistas, em quatro municípios de Goiás. 2012. 60f. Dissertação (Mestrado em Ciências Florestais) - Universidade de Brasília, Brasília, 2012.

SOUZA, M.R.M.; PEREIRA, R.G.F.; FONSECA, M.C.M. Comercialização de plantas medicinais no contexto da cadeia produtiva em Minas Gerais. Revista Brasileira de Plantas Medicinais, v. 14, n. spe, p. 242-245, 2012.

SOUZA-MOREIRA, T.M.; SALGADO, H.R.N.; PIETRO, R.C.L.R. O Brasil no contexto de controle de qualidade de plantas medicinais. Brazilian Journal of Pharmacognosy, v. 20, n. 3, p. 435-440, jun. 2010.

TRENTO FILHO, A.J.; MENON, M.U.; CORRÊA JUNIOR, C. Caracterização da produção de plantas medicinais, aromáticas e condimentares no Território CentroSul do Paraná. Revista Ambiência. Guarapuava (PR), v. 6, n. 3, p. 511-520. set./ dez. 2010.

USTULIN, M. et al. Plantas medicinais comercializadas no Mercado Municipal de Campo Grande-MS. Revista Brasileira de Farmacognosia, v. 19, n. 3, p. 805-813, 2009.

Recebido em: 13 de abril de 2014 Aceito em: 20 de abosto de 2014 


\section{ANEXO A}

\section{Tabela 3. Pesquisa Socioeconômica}

(continua)

\begin{tabular}{|c|c|c|}
\hline 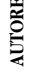 & METODOLOGIA & RESULTADOS E CONCLUSÕES \\
\hline 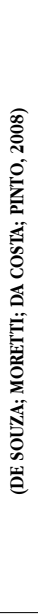 & $\begin{array}{l}\text { Metodologia: Para a caracterização das famí- } \\
\text { lias, utilizou-se o conceito de família nuclear, } \\
\text { ou seja, aquela constituída pelo casal, mais } \\
\text { filhos. O levantamento de dados socioeco- } \\
\text { nômicos das famílias assentadas foi realizado } \\
\text { empregando-se um questionário, contendo } \\
\text { perguntas abertas e fechadas, baseando-se } \\
\text { no modelo "Formulário do Beneficiário", } \\
\text { usado pelo Ipardes (2000) na avaliação das } \\
\text { vilas rurais do Estado do Paraná. Foram en- } \\
\text { trevistadas } 28 \text { famílias, na Vila Rural do Laje- } \\
\text { ado, e } 20 \text { famílias, na Vila Rural da Roseira. A } \\
\text { aplicação do questionário foi realizada entre } \\
\text { os meses de junho e setembro de } 2003 \text {, e } \\
\text { os dados foram tabulados em uma planilha } \\
\text { eletrônica. }\end{array}$ & $\begin{array}{l}\text { As explorações agropecuárias realizadas nas duas vilas são basica- } \\
\text { mente as mesmas, havendo maior ocupação da área do lote com a } \\
\text { produção de grãos, especificamente milho e feijão. A mão de obra } \\
\text { disponível nas duas vilas e subutilizada poderia estar sendo utiliza- } \\
\text { da em exploração mais intensiva no lote, no sentido de aumentar a } \\
\text { renda dos assentados. A experiência com cultivo de plantas medici- } \\
\text { nais (melissa) foi positiva para as famílias assentadas e representou } \\
\text { aumento na renda agrícola de } 34,09 \% \text {, na Vila Rural do Lajeado, e } \\
\text { de } 48,08 \% \text { na Vila Rural da Roseira. No entanto, o maior desafio } \\
\text { para implantar uma atividade que venha gerar mais renda para as } \\
\text { famílias consiste em vencer a característica cultural individualista e } \\
\text { a extrema pobreza. A forma e o tamanho das explorações realizadas } \\
\text { pelas famílias assentadas nas Vilas Rurais do Lajeado e da Roseira } \\
\text { não permitem comparar o resultado econômico com o potencial } \\
\text { agrícola das terras. }\end{array}$ \\
\hline 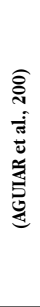 & $\begin{array}{l}\text { Através do referencial teórico da pesquisa } \\
\text { descritiva, adotou-se como método o estudo } \\
\text { de caso. A coleta de dados foi feita utilizan- } \\
\text { do-se entrevistas semiestruturadas, visitas a } \\
\text { campo e observação participante. }\end{array}$ & $\begin{array}{l}\text { Os sistemas agroflorestais tradicionais são bem adaptados às uni- } \\
\text { dades de produção familiares. Na Amazônia são mantidos através } \\
\text { de práticas tradicionais de cultivo, que permitem tanto a conser- } \\
\text { vação dos ecossistemas, quanto a perpetuação dos modos de vida } \\
\text { da população local, com seus costumes, mitos e outras formas de } \\
\text { manifestação cultural. Além disso, os sistemas agroflorestais apre- } \\
\text { sentam-se como uma forma de agricultura capaz de gerar renda e } \\
\text { mostra-se adaptada às condições ambientais da Amazônia. }\end{array}$ \\
\hline 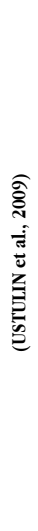 & $\begin{array}{l}\text { Levantamento de dados etnofarmacológicos } \\
\text { em várias ocasiões entre agosto de } 2002 \text { e } \\
\text { agosto de } 2003 \text {, através de entrevistas com } \\
\text { todos os raizeiros do Mercado Municipal de } \\
\text { Campo Grande (MS). Questionário previa- } \\
\text { mente elaborado de acordo com Schardong } \\
\text { (1999) e de modo imparcial com o objetivo } \\
\text { de dar maior liberdade ao entrevistado. Le- } \\
\text { vantamento bibliográfico e sistematização de } \\
\text { informações populares e científicas. Constru- } \\
\text { ção de uma tabela sobre os dados farmaco- } \\
\text { lógicos e etnofarmacológicos de plantas in- } \\
\text { dicadas pelos raizeiros e identificadas pelos } \\
\text { botânicos. }\end{array}$ & $\begin{array}{l}\text { Os resultados obtidos demonstram que as informações dos rai- } \\
\text { zeiros, quanto ao uso terapêutico das plantas citadas como me- } \\
\text { dicinais, coincidem em quase } 50 \% \text { com as indicações etnofarma- } \\
\text { cológicas encontradas na literatura; no entanto, somente } 34,8 \% \\
\text { têm alguma atividade farmacológica comprovada. As informações } \\
\text { etnofarmacológicas oferecem subsídios para estudos fitoquímicos, } \\
\text { farmacológicos e de controle de qualidade de plantas medicinais } \\
\text { comercializadas e são necessários para avaliação dos seus efeitos } \\
\text { farmacológicos e toxicológicos, buscando estratégias seguras para } \\
\text { o uso dessas plantas e para a produção de fitoterápicos. Somente } \\
\text { assim, as plantas medicinais chegariam aos usuários com compro- } \\
\text { vação da sua eficácia e ausência de toxidade. }\end{array}$ \\
\hline
\end{tabular}


(continua)

\begin{tabular}{|c|c|c|}
\hline 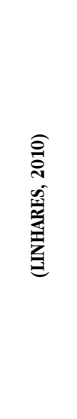 & $\begin{array}{l}\text { A metodologia consistiu de várias etapas: } \\
\text { formação de um banco de dados para o mu- } \\
\text { nicípio; caracterização das unidades de pai- } \\
\text { sagem e tipologias vegetacionais de ocorrên- } \\
\text { cia de Himatanthus; análise fitossociológica } \\
\text { para determinação de flora acompanhante; } \\
\text { aplicação de questionário etnobotânico para } \\
\text { caracterização do informante e do sistema de } \\
\text { extração de látex; extração experimental nas } \\
\text { áreas de ocorrência; estimativa dos custos de } \\
\text { produção; análise microbiológica. }\end{array}$ & $\begin{array}{l}\text { Medidas de manejo devem ser definidas e implementadas para } \\
\text { controle e exploração da espécie, proteção das áreas de ocorrên- } \\
\text { cia, melhoria do sistema de produção, tornando-o mais rentável } \\
\text { e seguro, do ponto de vista ambiental e da saúde pública. É ne- } \\
\text { cessária avaliação dos métodos utilizados tradicionalmente, com } \\
\text { determinação daquele que menos expõe o produto a fontes de } \\
\text { contaminação; estímulo à formação de associação de extrativistas; } \\
\text { efetiva fiscalização dos órgãos ambientais; e, por último, definição } \\
\text { e implementação de política de garantia de preço mínimo para o } \\
\text { produto. }\end{array}$ \\
\hline 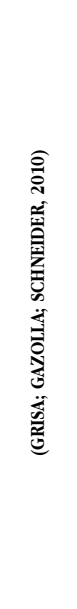 & $\begin{array}{l}\text { Metodologia: Estudo comparativo em que } \\
\text { foram investigados } 238 \text { estabelecimentos ru- } \\
\text { rais, nos quais foram aplicados questionários } \\
\text { semiestruturados. Levantamentos de dados } \\
\text { quantitativos. }\end{array}$ & $\begin{array}{l}\text { A produção para o autoconsumo está longe de ser «invisível» como } \\
\text { muitos estudos rurais do passado a definiram; ela é base importan- } \\
\text { te dos processos de manutenção das formas familiares no rural, } \\
\text { sejam estas mais ou menos integradas aos mercados. Ressalta-se } \\
\text { a necessidade das políticas públicas rurais brasileiras caminharem } \\
\text { neste mesmo sentido. Reafirma-se que o fortalecimento da agri- } \\
\text { cultura familiar passa por um conjunto de iniciativas dos próprios } \\
\text { agricultores enquanto atores sociais do seu próprio destino e de- } \\
\text { senvolvimento, mas também por ações ativas do Estado, principal- } \\
\text { mente em locais de maior vulnerabilidade social, que poderiam ser } \\
\text { mescladas com políticas de transferência de renda (Bolsa Família, } \\
\text { por exemplo), com políticas agrícolas que incentivam a produção } \\
\text { de mercadorias e também por políticas que incidem sobre outras } \\
\text { dimensões das famílias como a cultura, a sociabilidade, as relações } \\
\text { sociais, o trabalho e «produções invisíveis», como é o caso do au- } \\
\text { toconsumo. }\end{array}$ \\
\hline 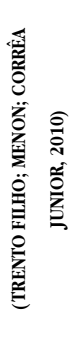 & $\begin{array}{l}\text { Aplicação de questionários (25) e identifica- } \\
\text { ção e definição dos locais de produção de } \\
\text { PM, somando-se as diversas espécies, distri- } \\
\text { buídas em } 142 \text { famílias utilizando } 92 \text { espé- } \\
\text { cies de PLAMAC. }\end{array}$ & $\begin{array}{l}\text { Verificou-se que a produção de plantas medicinais é desenvolvida } \\
\text { em } 75 \% \text { dos municípios do Território Centro-Sul do Paraná. Em } \\
67 \% \text { destes municípios que desenvolvem a atividade, os produ- } \\
\text { tores apresentam perspectivas de expansão e } 33 \% \text { consideram a } \\
\text { atividade estável. Prudentópolis é a região que concentra o maior } \\
\text { número de produtores e a camomila é a planta com maior área de } \\
\text { cultivo. O processo de secagem em alguns dos casos é coletivo, no } \\
\text { total estão instalados } 104 \text { secadores em todo o território, porém a } \\
\text { qualidade do processo de secagem precisa evoluir rapidamente. }\end{array}$ \\
\hline
\end{tabular}


(continua)

\begin{tabular}{|c|c|c|}
\hline 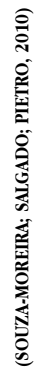 & $\begin{array}{l}\text { Levantamento bibliográfico e comparações } \\
\text { de estudos já realizados. }\end{array}$ & $\begin{array}{l}\text { O uso das plantas medicinais representa uma fonte de acesso em } \\
\text { potencial para as camadas mais carentes da sociedade e também } \\
\text { possibilita a descoberta de novas moléculas ou de novos tratamen- } \\
\text { tos de doenças que apresentem tratamento e/ou prognóstico difí- } \\
\text { ceis. Entretanto, assim como qualquer outro medicamento, aque- } \\
\text { les baseados em plantas devem comprovar sua eficácia e segurança } \\
\text { para uso, exigindo que procedimentos de controle de qualidade } \\
\text { sejam estabelecidos em toda a sua cadeia produtiva, desde o seu } \\
\text { plantio até a droga vegetal, ou fitoterápico, prontos para dispen- } \\
\text { sação. }\end{array}$ \\
\hline & $\begin{array}{l}\text { A pesquisa foi realizada em um fragmento } \\
\text { florestal localizado no município de Mon- } \\
\text { teiro (PB). Foi realizado um levantamento } \\
\text { florístico e fitossociológico do componente } \\
\text { arbustivo-arbóreo em uma área contígua de } \\
\text { caatinga que totaliza } 01 \text { hectare, com parce- } \\
\text { las de } 10 \mathrm{~m} \times 10 \mathrm{~m} \text {, totalizando } 100 \text { parcelas } \\
\text { de } 100 \mathrm{~m} 2 \text { cada, sendo anotados: a espécie, } \\
\text { a altura e o diâmetro dos indivíduos com } \\
\text { Circunferência a Altura da Base (CAB) } \geq 9 \\
\text { cm e altura } \geq 1 \text { m. Foram aplicados } 256 \text { ques- } \\
\text { tionários aos proprietários rurais do municí- } \\
\text { pio estudado, seguindo a área de cobertura } \\
\text { dos Agentes Comunitários de Saúde, visando } \\
\text { caracterizar os aspectos: socioeconômico, } \\
\text { ambiental e etnobotânico, além de um levan- } \\
\text { tamento das espécies medicinais nativas com } \\
\text { ênfase para sua utilidade, modo de preparo e } \\
\text { uso terapêutico. }\end{array}$ & $\begin{array}{l}\text { Constatou-se que a área estudada apresenta baixa riqueza florística, } \\
\text { com maior predominância de espécies do gênero Croton, indican- } \\
\text { do um estágio inicial de sucessão. Apesar da elevada percentagem } \\
\text { de famílias que utilizam fogão a gás, a utilização da lenha ainda } \\
\text { é predominante na região, demonstrando a necessidade de pro- } \\
\text { gramas de educação ambiental visando a conscientização da po- } \\
\text { pulação e o incentivo político e/ou privado ao cultivo e exploração } \\
\text { racional de espécies medicinais da caatinga. A eletrificação rural } \\
\text { proporcionou significativa melhoria da qualidade de vida e socio- } \\
\text { econômica da população rural de Monteiro (PB), pois foi possível } \\
\text { desenvolver técnicas eficazes de convivência com a seca, baseado } \\
\text { no cultivo de espécies forrageiras nativas, adaptadas à condição } \\
\text { climática da região e armazenamento da água das chuvas por meio } \\
\text { de cisternas de placa. }\end{array}$ \\
\hline 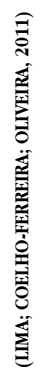 & $\begin{array}{l}\text { Levantamentos da comercialização de plan- } \\
\text { tas medicinais em } 10 \text { municípios da região. } \\
\text { Entrevistas semiestruturadas com } 20 \text { vende- } \\
\text { dores de plantas medicinais. Foi estimada } \\
\text { a riqueza de espécies a partir do estimador } \\
\text { Bootstrap e analisada a similaridade entre os } \\
\text { municípios estudados, através do Índice de } \\
\text { Sørensen. }\end{array}$ & $\begin{array}{l}\text { Apesar de o número de etnoespécies observado ser expressivo, a } \\
\text { realização de mais entrevistas seria importante para se atingir a su- } \\
\text { ficiência amostral que, de acordo com o índice Bootstrap, seria de } \\
\text { pelo menos quatro ocorrências a mais. Existe variação na riqueza } \\
\text { de plantas medicinais entre os municípios estudados. Há de se res- } \\
\text { saltar que o comércio constitui uma das opções de atividades para } \\
\text { trabalhadores no setor informal, em um contexto justificado pela } \\
\text { sobrevivência, devido às dificuldades de obtenção de renda, sendo } \\
\text { que alguns atores dependem de recursos extras, como benefícios } \\
\text { de programas sociais do Governo Federal. }\end{array}$ \\
\hline
\end{tabular}


(continua)

\begin{tabular}{|c|c|c|}
\hline 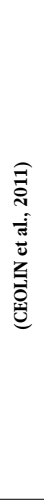 & $\begin{array}{l}\text { Trata-se de um estudo qualitativo realizado } \\
\text { com oito famílias de agricultores, totalizando } \\
19 \text { entrevistados, residentes nos municípios } \\
\text { de Pelotas, Morro Redondo, Canguçu e Ar- } \\
\text { roio do Padre, entre janeiro e maio de } 2009 \text {. } \\
\text { A análise dos dados foi realizada através do } \\
\text { método hermenêutico-dialético. Aplicação } \\
\text { de entrevistas pré-agendadas, semiestrutura- } \\
\text { das, construção de genograma e eco-mapa; } \\
\text { a observação sistemática das plantas com } \\
\text { registro fotográfico, georreferenciamento e a } \\
\text { observação de campo. }\end{array}$ & $\begin{array}{l}\text { A construção do conhecimento relacionado ao uso de plantas me- } \\
\text { dicinais pelas famílias de agricultores é predominantemente oral, } \\
\text { realizada através do convívio diário entre seus membros, propician- } \\
\text { do a transmissão de informações, crenças e valores. A conservação } \\
\text { da transmissão do saber popular sobre as plantas depende de } \\
\text { como ele continuará sendo repassado. Buscar integrar o saber po- } \\
\text { pular e o científico na realização do cuidado, desenvolvendo uma } \\
\text { assistência integral que compreenda o contexto cultural no qual o } \\
\text { indivíduo e a sua família estão inseridos, realizando a promoção da } \\
\text { saúde e a melhoria da qualidade de vida. O profissional necessita } \\
\text { ter conhecimento sobre a identificação de plantas, os princípios } \\
\text { ativos e contraindicações de cada planta, levando em consideração } \\
\text { o conhecimento local, incluindo a diversidade de nomes. }\end{array}$ \\
\hline 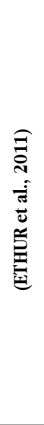 & $\begin{array}{l}\text { Diagnóstico do perfil dos usuários de plantas } \\
\text { medicinais, através de questionário semies- } \\
\text { truturado que foi aplicado a } 183 \text { pessoas } \\
\text { abordadas em áreas de circulação de mora- } \\
\text { dores de todos os bairros do município. Ava- } \\
\text { liou-se a comercialização e visão do comércio } \\
\text { formal nas oito farmácias do município. }\end{array}$ & $\begin{array}{l}\text { Observou-se que } 71 \% \text { dos entrevistados ficaram na faixa etária de } \\
21 \text { a } 60 \text { anos e que a grande maioria apresenta renda mensal de } \\
\text { até três salários mínimos; a compra de fitoterápicos e plantas me- } \\
\text { dicinais era realizada praticamente por mulheres, das quais } 75 \% \\
\text { adultas e } 25 \% \text { idosas. Os chás mais vendidos foram principalmente } \\
\text { os emagrecedores e digestivos e o valor gasto com esse tipo de } \\
\text { produto ficou na faixa de } \$ \$ 1,00 \text { a } \$ \$ 3,00 \text {. Conclui-se que existe } \\
\text { mercado para plantas medicinais e fitoterápicos e necessidade de } \\
\text { maiores informações referentes à forma de cultivo, correta identi- } \\
\text { ficação botânica, informações ao consumidor, qualidade e eficácia } \\
\text { dos produtos e seu uso. }\end{array}$ \\
\hline & $\begin{array}{l}\text { O presente trabalho foi estruturado a partir } \\
\text { de um estudo de caso, valendo-se de abor- } \\
\text { dagem quali-quantitativa que possibilitou } \\
\text { tomar conhecimento da realidade de vida } \\
\text { dos atores sociais envolvidos no projeto da } \\
\text { Associação de Produtores de Plantas Medici- } \\
\text { nais de Santo Ângelo (RS). }\end{array}$ & $\begin{array}{l}\text { As ações de estratégias de reprodução social local geram ganho } \\
\text { financeiro e social. Ações pensadas nestes processos de desenvolvi- } \\
\text { mento, como no caso em tela, a constituição de uma Associação - a } \\
\text { APLAME - através de um Projeto Político-Pedagógico que integra o } \\
\text { sistema de produção, cultivo e comercialização de plantas medi- } \\
\text { cinais, é uma estratégia de reprodução social local, cujo resulta- } \\
\text { do gera desenvolvimento diferenciado que pode ser medido nas } \\
\text { ações: resgate familiar/cultural no uso das plantas medicinais, troca } \\
\text { de experiências, conhecimento técnico de produção, incentivo do } \\
\text { setor público e parcerias. É importante considerar que os ganhos } \\
\text { advindos da integração social desse grupo é um dos aspectos de } \\
\text { reconhecida relevância do ponto de vista do desenvolvimento hu- } \\
\text { mano. }\end{array}$ \\
\hline
\end{tabular}


(continua)

\begin{tabular}{|c|c|c|}
\hline & $\begin{array}{l}\text { Baseou-se em entrevistas e observações, } \\
\text { usando-se questionários semiestruturados, } \\
\text { contendo perguntas abertas e/ou fechadas, } \\
\text { aplicadas em forma de diálogo. As visitas fo- } \\
\text { ram in loco, realizadas no período de outu- } \\
\text { bro e novembro de } 2011 \text {. Foram amostradas } \\
80 \text { unidades familiares de agroextrativistas. A } \\
\text { amostra foi definida aleatoriamente. As espé- } \\
\text { cies foram agrupadas em categorias de uso } \\
\text { e foram calculados os índices de diversidade } \\
\text { de Shannon-Wiener, de similaridade de Jac- } \\
\text { card e de Sorensen. }\end{array}$ & $\begin{array}{l}\text { A análise permitiu ressaltar alguns aspectos relacionados à dinâmi- } \\
\text { ca socioeconômica e ambiental das atividades de extrativismo não } \\
\text { madeireiro. Entre os pesquisados, } 72,5 \% \text { se declararam depender } \\
\text { economicamente da extração e } 27,5 \% \text { do artesanato de produtos } \\
\text { extraídos; } 75 \% \text { das famílias possuem entre } 1 \text { a } 15 \text { anos de trabalho } \\
\text { na produção florestal não madeireira na região; } 69 \% \text { disseram que } \\
\text { não encontraram outra fonte de renda; } 80 \% \text { afirmaram receber } \\
\text { recursos do programa de transferência de renda Bolsa Família; e } \\
20 \% \text { confirmaram ter recursos de correspondente aposentadoria. A } \\
\text { participação da exploração florestal não madeireira na composição } \\
\text { da renda da família é de } 100 \% \text {. Quanto à comercialização de plan- } \\
\text { tas medicinais, foi registrada a presença de } 18 \text { espécies de plantas } \\
\text { úteis, distribuídas em } 10 \text { famílias botânicas. }\end{array}$ \\
\hline 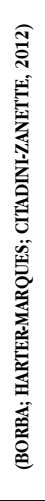 & $\begin{array}{l}\text { O levantamento de dados incluiu visitas a } \\
\text { campo, observação participante e entrevis- } \\
\text { tas semiestruturadas, com um produtor de } \\
\text { plantas medicinais. O estudo de caso foi } \\
\text { realizado com um produtor pioneiro no cul- } \\
\text { tivo ecológico de plantas medicinais de uma } \\
\text { propriedade particular localizada na zona } \\
\text { rural do município de Grão-Pará. Buscou-se } \\
\text { caracterizar o histórico da produção, utiliza- } \\
\text { ção da planta pela família, sistema de plantio, } \\
\text { controle de pragas, produção e comercializa- } \\
\text { ção, a renda do produtor e incentivos gover- } \\
\text { namentais referentes à calêndula. }\end{array}$ & $\begin{array}{l}\text { Constatou-se que o agricultor optou por dar início à produção } \\
\text { orgânica em sua propriedade, com ênfase na produção de plan- } \\
\text { tas medicinais. A atividade rural desenvolvida conta com a família, } \\
\text { responsável por todas as etapas da produção, sendo boa parte da } \\
\text { produção destinada à comercialização. A produção de plantas me- } \\
\text { dicinais como meio de renda ainda é relativamente baixa. Identi- } \\
\text { ficaram-se como principais particularidades a saúde na agricultura } \\
\text { familiar, demonstrada pela prática da cultura orgânica, além do } \\
\text { controle de pragas e manuseio da produção. Constata-se a ausên- } \\
\text { cia de informações do produtor quanto a incentivos governamen- } \\
\text { tais ao setor agrícola. }\end{array}$ \\
\hline 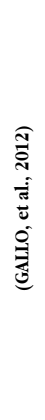 & $\begin{array}{l}\text { Concepção teórica, levantamento bibliográfi- } \\
\text { co, revisão crítica. }\end{array}$ & $\begin{array}{l}\text { A transição para uma economia sustentável depende de decisões } \\
\text { políticas e vai além do desenvolvimento de tecnologias, devendo } \\
\text { implantar um novo modo de produção, consumo e organiza- } \\
\text { ção social que promova a justiça socioambiental, incentivando a } \\
\text { participação social e as formas democráticas de governança para } \\
\text { definir uma agenda concreta de implementação de objetivos para } \\
\text { o desenvolvimento sustentável e de mecanismos capazes de im- } \\
\text { plementá-los em todos os níveis. Em um cenário onde os serviços } \\
\text { ecossistêmicos vão sendo perdidos e há graves iniquidades sociais } \\
\text { é necessário um novo modelo de crescimento capaz de promover o } \\
\text { desenvolvimento social com a redução da pegada ecológica. }\end{array}$ \\
\hline
\end{tabular}


(continua)

\begin{tabular}{|c|c|c|}
\hline 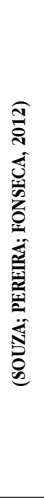 & $\begin{array}{l}\text { Entrevistas semiestruturadas com um roteiro } \\
\text { baseado em questões relacionadas às condi- } \\
\text { ções de oferta e demanda das plantas medi- } \\
\text { cinais pelos comerciantes e consumidores, } \\
\text { informações relacionadas à compra e venda } \\
\text { dos produtos medicinais, padrões de preço, } \\
\text { quantidade, qualidade e fatores que influen- } \\
\text { ciam a disponibilidade dos produtos no mer- } \\
\text { cado. Para realização desta pesquisa, foram } \\
\text { selecionadas algumas espécies registradas } \\
\text { pela ANVISA e que fazem parte do Programa } \\
\text { Estadual Componente Verde. }\end{array}$ & $\begin{array}{l}\text { Os resultados demonstraram a precariedade desse setor quanto } \\
\text { à obtenção das plantas medicinais, principalmente pela falta de } \\
\text { conhecimento e informações na aquisição e venda dos produtos } \\
\text { pelos consumidores e vendedores, respectivamente. Informações } \\
\text { chegam de forma incompleta, resultando em equívocos quanto à } \\
\text { identificação correta e, consequentemente, quanto ao uso medici- } \\
\text { nal. Outro problema na aquisição das plantas foi a situação da cer- } \\
\text { tificação da qualidade, que no geral foi considerada baixa. Acredita- } \\
\text { se que o aumento do consumo das plantas medicinais e as políticas } \\
\text { e programas governamentais devam ser vistos como oportunidades } \\
\text { para alternativas de renda na produção familiar e, portanto, devem } \\
\text { ser melhor divulgados, diante da falta de conhecimentos e informa- } \\
\text { ções constatadas na aquisição e venda dos produtos. }\end{array}$ \\
\hline & $\begin{array}{l}\text { Estudo de caso e entrevistas baseado em uma } \\
\text { análise comparativa de duas iniciativas de di- } \\
\text { ferentes regiões do Brasil (Minas Gerais, Goi- } \\
\text { ás, Tocantins e Maranhão). Seleção de grupos } \\
\text { representativos por uma rede social chama- } \\
\text { da Articulação Pacari. Também envolveu co- } \\
\text { munidades ribeirinhas, quilombolas, grupos } \\
\text { de quilombolas e tribos indígenas que vivem } \\
\text { no Estado do Amapá na floresta amazônica. } \\
\text { O trabalho de campo nas instalações IEPA } \\
\text { foi conduzido para examinar as iniciativas } \\
\text { tomadas para facilitar o desenvolvimento das } \\
\text { comunidades. }\end{array}$ & $\begin{array}{l}\text { Parece que mesmo IEPA tenha iniciativa de incluir as comunidades } \\
\text { locais no mercado formal não leva em conta potencialmente enor- } \\
\text { mes oportunidades de venda de drogas produzidas localmente e } \\
\text { cosméticos para outros estados brasileiros e para o mercado regio- } \\
\text { nal do Mercosul. Portanto, parece bastante incipiente, a partir de } \\
\text { uma perspectiva de negócio. Também é verdade que, se as comu- } \\
\text { nidades locais começaram a fabricar esses medicamentos em uma } \\
\text { escala maior, a colheita sustentável e preservação da biodiversidade } \\
\text { se tornou uma grande preocupação. Ainda assim, o lento desen- } \\
\text { volvimento de ambos IEPA e Articulação Pacari são iniciativas que } \\
\text { mostram que as oportunidades de negócios são ainda muito pouco } \\
\text { exploradas no Brasil. }\end{array}$ \\
\hline 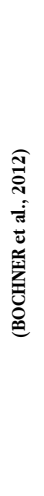 & $\begin{array}{l}\text { Trabalho documental, de } \\
\text { exploratório. }\end{array}$ & $\begin{array}{l}\text { Apesar do presente estudo se restringir às } 20 \text { espécies mais co- } \\
\text { mercializadas em agosto de } 2008 \text { no Mercadão de Madureira, os } \\
\text { resultados observados podem ser generalizados. Dentre as plantas } \\
\text { estudadas, as espécies babosa, boldo-do-Chile, camomila, confrei, } \\
\text { espinheira-santa e guaco constam da lista de medicamentos fito- } \\
\text { terápicos de registro simplificado e, por essa razão, não necessi- } \\
\text { tam validar as indicações terapêuticas e segurança de uso (Anvisa, } \\
2008 \text { ). Já para o consumo direto dessas plantas pela população } \\
\text { todos os problemas associados ao processo produtivo estão pre- } \\
\text { sentes. O comércio de plantas embaladas e rotuladas ainda é bas- } \\
\text { tante precário. Diversas plantas medicinais já contam com muitos } \\
\text { estudos abordando tanto as propriedades farmacológicas quanto } \\
\text { os efeitos tóxicos. }\end{array}$ \\
\hline
\end{tabular}


(continua)

\begin{tabular}{|c|c|c|}
\hline 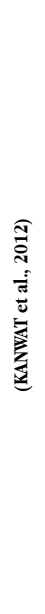 & $\begin{array}{l}\text { Este estudo foi realizado com o propósito } \\
\text { de identificação de fatores socioeconômicos } \\
\text { eficazes na adoção de cultivo de plantas me- } \\
\text { dicinais na divisão de Udaipur de Rajasthan, } \\
\text { na Índia. A pesquisa foi realizada por meio de } \\
\text { amostragem aleatória estratificada para cole- } \\
\text { tar dados de agricultores rurais selecionados } \\
\text { em Udaipur e na região de Chittorgarh, Sul } \\
\text { Rajasthan, na Índia. Temas em estudo foram } \\
\text { divididos em dois grupos: um com atividade } \\
\text { no cultivo e outro que não adota o cultivo. } \\
\text { Um total de } 50 \text { adotantes e } 40 \text { não adotantes } \\
\text { foram estudados para validar fatores efetivos. }\end{array}$ & $\begin{array}{l}\text { Os resultados mostraram que os fatores socioeconômicos mais im- } \\
\text { portantes no cultivo de plantas medicinais em Udaipur, divisão da } \\
\text { província, são referentes à idade, forma de ocupação, renda anual } \\
\text { das atividades agrícolas e sistema de utilização. Sugere-se promo- } \\
\text { ver de forma mais eficaz o cultivo de plantas da cultura medici- } \\
\text { nal. Resultados mostram quatro fatores importantes na diferença } \\
\text { econômica entre os dois grupos de adotantes e não adotantes de } \\
\text { plantas medicinais na região estudada. Para que haja mais adeptos } \\
\text { ao cultivo de plantas, deve-se fornecer recursos financeiros, insta- } \\
\text { lações e materiais necessários, a fim de desenvolver o cultivo de } \\
\text { plantas medicinais e torná-lo mais valioso. Finalmente, a abundân- } \\
\text { cia de plantas medicinais da região estudada faz com que sejam } \\
\text { cultivadas descontroladamente; sugere-se estudar mais sobre téc- } \\
\text { nicas de cultivo planejadas em propriedades rurais e determinar as } \\
\text { necessidades específicas da cultura, como requisitos específicos de } \\
\text { plantio, manutenção e colheita. }\end{array}$ \\
\hline 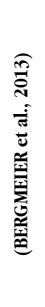 & $\begin{array}{l}\text { Neste trabalho, um total de } 106 \text { espécies de } \\
\text { plantas etnomedicinais, pertencentes a } 54 \\
\text { famílias de plantas, foram catalogadas. Uma } \\
\text { parte considerável das espécies de plantas e } \\
\text { remédios etno-medicinais refere distúrbios } \\
\text { gastro- intestinais. Os remédios eram em sua } \\
\text { maioria preparados na forma de decocção ou } \\
\text { pó e administrados por via oral }\end{array}$ & $\begin{array}{l}\text { Verificou-se que as plantas medicinais são amplamente usadas lo- } \\
\text { calmente, mas sujeitas cada vez mais à redução devido ao reflo- } \\
\text { restamento. A sugestão encontrada é implementar sistemas loca- } \\
\text { lizados menores para cultivo de espécies vulneráveis e comercial- } \\
\text { mente viáveis sob responsabilidade de intervenção governamental. }\end{array}$ \\
\hline
\end{tabular}

